\title{
Endothelial Stem and Progenitor Cells for Regenerative Medicine
}

Kimihiko Banno, $\mathrm{MD}, \mathrm{PhD}^{11}$, Mervin C. Yoder, $\mathrm{MD}^{2}$.

1) Department of Cellular \& Integrative Physiology, Indiana University School of Medicine

2) Indiana Center for Regenerative Medicine and Engineering, Indiana University School of Medicine

\section{Corresponding Author}

Kimihiko Banno

1044 W. Walnut St, R4-W005C

Indianapolis, IN 46202

kbanno@iu.edu

Mervin C. Yoder

975 W. Walnut St, IB-454B

Indianapolis, IN 46202

myoder@iu.edu

This is the author's manuscript of the article published in final edited form as:

Banno, K., \& Yoder, M. C. (2019). Endothelial Stem and Progenitor Cells for Regenerative Medicine. Current Stem Cell Reports, 5(3), 101-108. https://doi.org/10.1007/s40778-019-00160-3 


\section{Keywords}

Vascular endothelial stem cell (VESC); Endothelial colony-forming cell (ECFC);

Endothelial progenitor cell (EPC)

\section{Human and Animal Rights}

This article is a review and does not contain any unpublished studies with human or animal subjects. All of the published works referenced contain notation on proper conduct of animal or human subjects from their institutions. 


\section{Abstract}

Purpose of Review: Vascular endothelial stem (VESC) and progenitor cells are emerging as local resident regulators of vascular endothelial repair and replacement in mammalian subjects. However, widely recognized and accepted standard measures of stem cell function have yet to be published and thus, we summarize some recent evidence that VESCs demonstrate stem cell properties in the process of EC lineage emergence, repair, and regeneration.

Recent Findings : Some rare resident ECs have been identified that are quiescent and reside within blood vessels, but are activated and proliferate in response to injury. Transcriptome analyses of these ECs at a single cell level are providing new insights into VESC identity, including tissue specific EC heterogeneity.

Summary: Blood vessels and circulating blood contain rare immature EC that display stem cell potential. Continuous efforts to define their precise location, origin, surface marker and molecular signatures would enhance current approaches for purification of cells that would enable us to build new vessels for regenerative medicine. 


\section{Introduction}

Endothelial cells (ECs) form the inner cellular lining of blood vessels. They are not merely a tubular conduit for blood cells and plasma. EC phenotypes are differentially regulated in space and time, giving rise to EC heterogeneity within tissues and organs [1]. Accumulating evidence indicates some rare ECs in a variety of tissues, display high proliferative potential in mouse, rat and human subjects [2-6]. These EC give rise to the endothelial proliferation identified within mammalian blood vessels during development and in response to injury. However, when, where and how this proliferation starts and distributes within the endothelium are still not clear. The concept that endothelial progenitor cells (EPCs) exist in adult animals and may participate in vascular repair gained great basic and translational interest from a report published by Asahara and colleagues in 1997 [7]. Over the past 2 decades, advances in methods and tools for lineage fate tracing, confocal microscopy, molecular signature identification, and transplantation into various mouse models of human disease have permitted clarification and delineation of the vascular EC hierarchy consisting of stem, progenitor, and mature endothelial states within the vasculature [8-10].

In this review, we first examine the emerging methods to identify stem cell potential for 
the EC lineage. Second, we summarize the recent advances for identifying resident VESCs in tissue and circulation. Third, we provide overview of some current advances that derive proliferative EC via direct somatic cell reprogramming or via pluripotent stem cells (PSCs). Finally, we provide an update on limitations for translating the currently available VESC for regenerative medicine.

\section{Vascular endothelial stem and progenitor cells}

Stem cells are generally defined as undifferentiated clonogenic cells capable of producing differentiated daughter cells and retaining their stem cell identity by self-renewal [11, 12]. Lineage-specific stem cells maintain themselves by clonal proliferation and contribute to all of the cell types of a specific lineage within a particular tissue or organ niche [13]. Here, we propose that endothelial lineage stem cells need to meet the following stem cell criteria: a) self-renewal ability, b) in vitro clonal proliferation (that can be shown by EC colony-forming potential upon re-plating at a single cell level), and c) in vivo potential of functional vessel-formation (including arterial, venous and capillary ECs) in recipient hosts (Fig. 1) [8]. Additional data that functionally confirms the above criteria include; d) isolation of the primary perfused donor-derived vessels and secondary clonal EC colony formation in vitro, and e) secondary in vivo vessel-formation 
by clonal transfer of the isolated primary donor-derived vasculature (Fig. 1). To delineate between VESC and vascular EPCs is not straight forward. We will present evidence and an emerging consensus that investigators need to be more prudent in using the term "EPCs" and restrict the use of the term for only those cells that display in vitroclonogenic (single cell colony-forming) potential and in vivo vessel-forming potential [14, 15].

This cautious restriction for the use of the term EPC to only those cells that display clonogenic and vessel forming potential is required if one follows the criteria for identifying stem and progenitor cells for the EC lineage $[11-13,15,16]$. Historically, EPCs have been isolated by cell sorting or in vitro cell culture [15, 17]. Although CD34 is frequently used as a cell surface marker for isolating EPCs, CD34+VEGFR-2 $(\mathrm{KDR})+\mathrm{CD} 133+$ cells are highly enriched in hematopoietic progenitor activity and do not give rise to any bona fide endothelial cell colonies in vitro $[18,19]$. There is still debate about the most appropriate markers that define an EPC in the blood stream, with some of the discussion constrained by the lack of consensus on EPC definition [15, 20-22]. Cell culture is an alternative approach to obtain EPCs, enables expansion of cell numbers, and is based upon cell adhesion to specific substrates in specialized media [23]. Using this in vitro approach, at least two distinct types of "EPCs" with different angiogenic 
properties have been identified: "early EPCs" (or myeloid angiogenic cells [MACs]) and "late EPCs" (or endothelial colony-forming cells [ECFCs]) [24-27]. While "early EPCs" represent hematopoietic cells that support endothelial repair and regeneration in injured vessels through largely proangiogenic paracrine mechanisms [15, 28, 29], "late EPCs" (ECFCs) are committed to an endothelial lineage fate and have significant proliferative and de novo vasculogenic potential [30-34]. Only "late EPCs" (ECFCs) can display in vitro clonogenic potential and in vivo vessel-forming potential [30-34]; functional capacities that "early" EPCs lack. Therefore, the only population that has all the characteristics of a bona fide "EPC" is the ECFCs [2, 31, 33, 35-38].

Although there are increasing number of clinical trials using the common term "EPC" as a therapeutic agent, clinicians need to be aware that methods and cell types used in the clinical studies often vary significantly [39] and none of the studies have been conducted with ECFC (that display clonal proliferative potential and in vivo vessel formation). A recent search for clinical trials using human EPC [39] on www.clinicaltrials.gov registry (22/09/05-12/04/17) identified 341 clinical trials: most were non-interventional observational trials to measure EPC levels across various clinical states, but 26 trials utilized EPC as a therapeutic agent. Half of the trials (12) were listed as complete and 
the other trials were either terminated, active, recruiting, or unknown. A total of 317 participants were registered and completed in 8 trials, and 9 papers were published [4048]. Some clinically beneficial improvements in the EPC treatment group were observed in 7 out of 8 published trials and most of the registered participants showed no severe complications [40-48]. However, none of the studies were powered to provide sufficient evidence for conduct of further larger clinical trials leading to recommendations for changes in clinical practice. When searching PubMed and Web of Science databases (01/05/2008-01/05/2018), 5 additional relevant clinical trials using "EPC" as a test cell therapy were carefully reviewed by Keighron et al [39, 47, 49-52]. They found the cell types used in all the five published trials differed in the methods of cell isolation and culture, as well as the cell surface markers used for phenotypic characterization. Four of the five trials were single arm early phase studies designed to show safety and feasibility of EPC therapy. All five studies reported that EPC therapy was safe and some identified improvements in treated patients. However, the cell dose and the route of administration was also different between these trials [39, 52, 49-51, 47]. These differences made it difficult to compare efficacy and approach among the trials. Keighron et al. [39] called for a more detailed definition of "EPC" to be used in future trials, as recently published by Medina et al [15], if a better understanding of the potential clinical benefit of an "EPC" 
based therapy is to be gained.

\section{Resident endothelial stem and progenitor cells}

In many organs and tissues, lineage-specific stem cells have been identified to reside in the tissue and to produce differentiated daughter cells and to retain their stem cell identity by self-renewal [53-56]. These resident stem cells survive in a quiescent state and begin to proliferative in response to tissue damage [57]. A similar idea may also be applicable for the endothelial-lineage. Over 4 decades ago, some studies already indicated non-random proliferating cell clusters were present in vessels even at homeostasis, though the overall basal rate of endothelial cell replication is negligible in adult animals $[58,59]$. The responses of large arteries or veins to denudation injury have been examined and the intimal injury was repaired via viable endothelial cells from the edge of the wound with subsequent endothelial cell expansion within the wound site [60,

61]. However, detailed cellular and molecular dynamics during this regenerative process have been lacking. McDonald et al. recently addressed some of these questions through a combination of multi-color lineage tracing, parabiosis, and single-cell transcriptomics analysis of aortic endothelial cells [9]. They utilized Cdh5 promotor driven tdTomatoexpressing mice that were induced immediately prior to injury and showed that labeled 
ECs post-injury gave rise to essentially all of the regenerated endothelial lining. To prove whether these ECs are derived from resident cells or via the circulation from distant sites, they used pairs of GFP+ and GFP- mice that were surgically parabiosed to share a chimeric circulation and observed that the regenerated aortic endothelial lining contained no contributions from distant sites. These findings clearly revealed that local resident ECs, but not circulating bone marrow derived "EPCs", contribute to regenerate EC lining in the aorta of their adult mice model. Intriguingly, they found there are at least two EC populations which differed in proliferative potential and thus implicated the existence of an EC hierarchy in the resident tissue. In their single cell RNA-seq (scRNA-seq) analysis of aortic EC in unwounded young and old mice, Atf3-positive cells that were enriched in the young endothelium correlated with higher expression of Fox, Jun, Egr1, Klf4, and Klf2, suggesting this gene may play a role to activate quiescent ECs to re-enter cell cycle for the injury regeneration response.

Although the study of McDonald et al [9] was primarily focused on mouse aorta EC response to injury, others have begun to identify vascular resident stem cells (VESC) in several different tissues and organs. Naito et al. reported the identification of resident vascular stem/progenitor cells in the side population (SP) of lung, liver, heart, and hind 
limb muscle cells [5]. The SP as a marker of stem cells was first identified by Goodell et al.[62] as bone marrow cells effluxing Hoechst 33342 dye through ATP-cassette transporter receptors and this subset contained dormant bone marrow hematopoietic stem cells. Naito et al. showed that resident quiescent EC stem/progenitor cells are found within SP cells by in vitro single cell assays for clonogenic potential and in vivo vesselformation assay [5,8]. Their group subsequently identified CD157 as a cell surface marker of tissue-resident VESC in large arteries and veins of several mouse organs [8]. Starting from the evidence that endothelial-SP cells are enriched with CD157 and CD200 expression, they revealed that liver CD157+CD200+ ECs exhibit a high proliferative potential in vitro and reconstitute portal vein, central vein, and sinusoid as well as capillaries after in vivo transplantation in a rodent liver injury model. They also performed donor cell transplantation at a single cell level and 3 of 350 transplanted CD157+CD200+ cells could generate functional donor-derived blood vessels, and EC progeny contained some CD157+CD200+ cells implicating their self-renewal potential.

Other cell surface markers including c-Kit (CD117) [6] and Protein C Receptor (Procr, CD201) [63] have also been investigated as VESC markers. Fang et al. found that c-Kit positive ECs from mouse lung tissue display 10-fold greater colony-forming potential 
compared to c-Kit negative ECs. They also observed that all EC colonies originated from vessel wall c-Kit+ ECs and are not produced by hematopoietic stem or progenitor cells. However, no fate mapping studies to identify the contributions of the c-Kit+ ECs within various vascular beds was presented and this marker seems to be not highly specific, since overall colony-formation efficiency was low. Yu et al. [63] identified that Procr positive ECs reside as VESC in murine mammary fat pad, skin, and retina. Procr+ VESCs exhibit robust clonogenicity in culture, high vessel reconstitution efficiency in transplantation, and long-term clonal expansion in lineage tracing studies in vivo.

The different cell surface protein candidates selected for enriching VESCs in the above studies $[6,8,63]$ may reflect tissue specific EC heterogeneity since each study mainly focused on an individual organ, such as, mouse lung [6], mammary fat pad [63], or liver [8], respectively. This notion is supported by some recent scRNA-seq analyses for several organs $[64,65]$, indicating tissue-specific gene regulatory architecture of each EC subtype from brain, liver, lung, and kidney [65]. Taken together, all of these recent advances in this field are paving the way for providing tools to identify VESC and providing models through which the stem cell properties may be distinctly identified. 


\section{Circulating endothelial stem cells (circulating ECFCs)}

As noted above, accumulating evidence indicates that many of the putative circulating marrow-derived EPCs contribute to neovascularization by a paracrine manner and fail to display vasculogenic activity by themselves. Rather, this property is reserved for circulating ECFCs, a rare population of viable endothelial cells with colony-forming cell ability in the blood stream [15, 28, 33, 36, 66]. Cord blood and peripheral blood ECFCs are well-known circulating ECFCs and can be derived from blood mononuclear cells and possess robust proliferative potential and capacity to form new blood vessels in vitro and in vivo [2, 31, 32, 37, 67].

Since the resident VESCs are identified as the main players for repairing tissue damage in mammalian wounded aorta and liver $[8,9,68]$, it is still elusive how the circulating ECFCs contribute to angiogenesis and vasculogenesis in physiologic and pathologic conditions. One obvious point, is that while there is no evidence that mouse circulating ECFCs are recruited to an injured site [9], a number of studies of human ECFC point to circulating ECFC as playing a role in health and disease [22, 23, 33, 34]. Campenelli et al [69]. measured the frequency and vasculogenic potential of circulating ECFC in infantile haemangioma (IH) patients, and showed that circulating ECFCs of untreated IH patients had a lower frequency than those of control subjects but displayed enhanced 
capacity to form tube-like structures. After propranolol therapy, they had increased frequency and a reduction of their vasculogenic activity. These results suggest a recruitment of circulating ECFCs from peripheral blood to the site of lesion caused their reduced frequency at diagnosis, and involution of the tumor mass, decrease in ECFC recruitment function, and/or a direct action of propranolol might cause an increased frequency and diminished vessel-formation capacity of circulating ECFCs [69]. A contribution of circulating ECFC can be found in the studies of measuring ECFC levels in preterm infants with bronchopulmonary dysplasia (BPD) [70-72]. The number of CBECFCs in preterm babies who subsequently developed BPD were significantly decreased $[70,71]$. Because impaired vascular growth has a main role in the pathogenesis of BPD, decreased ECFCs may contribute to abnormal vascular repair. Administration of CBECFCs into a rat pup model of BPD, shown to be deficient in ECFCs, reversed the disease phenotype dramatically through their contribution to lung neovascularization [72]. Taken together, circulating ECFCs are proposed to contribute to vessel formation both physiologically and pathologically, and giving external circulating ECFCs may be an effective treatment for building up the new vessels for tissue regeneration in subjects with dysfunctional vascular repair or regeneration. 


\section{Proliferative ECs via direct somatic cell reprogramming or via pluripotent stem cells}

To generate high-proliferative EC by forced expression of transcriptional factor (s) or chemicals via direct somatic cell reprogramming or via differentiation from human pluripotent stem cells (PSCs) has become an increasingly important topic in the field of regenerative medicine. Direct reprogramming of fibroblasts into ECs was first reported by Margariti et al. [73]. They partially reprogrammed fibroblasts and let them differentiate into ECs that expressed EC cell surface markers and upon injection, improved mouse ischemic tissue recovery. Their study paved the way for many other approaches. Ginsberg et al [74]. reported that enforced expression of ETV2, FLI1, and ERG1 with TGF $\beta$ inhibition changed the fate of amniotic mesenchymal cells to EC-like cells. Their optimized protocol enabled the reprogrammed ECs to display single-cell clonogenic potential in vitro and form functional perfused vessels in vivo. Benefits for the use of ETV2 as the master regulator for EC fate conversion from other cell lineages has also been proposed by other groups $[75,76]$. Two groups succeeded to derive reprogrammed ECs that upon injection, improved mouse hindlimb recovery after an experimentally induced ischemia injury, but the ideal duration and/or dose of ETV2 transgene expression to induce sufficient endothelium remains unknown [77, 78]. A better understanding and accurate tuning of ETV2 delivery, alone or with other 
reprogramming molecules, should enhance the outcomes for the desirable direct reprogramming EC fate change. As one example, a recent very innovative approach to in vivo tissue reprogramming was reported by Gallego-Perez et al. [79]. This group developed a novel non-viral approach to topically reprogram tissues through a nanochannelled silicone ship through which a variety of molecules can be delivered to reprogram keratinocytes into neuron-like or EC-like cells. Fate mapping evidence confirmed that keratinocyte cells contributed to blood vessels and neurons within the tissues. The functional impact of the reprogramming was sufficient to rescue animals with experimentally induced wounds to heal those wounds significantly better than appropriate controls [79].

Prasain et al [80]. reported on a detailed culture protocol using BMP4, VEGF, and bFGF to differentiate human induced pluripotent stem cells (hiPSCs) towards ECs that molecular, phenotypic, and function features similar to CB-ECFCs. This protocol focused on isolation of CD31+Neuropilin-1 (NRP-1)+ after 12 days differentiation from hiPSCs. The derived ECs displayed clonal proliferative potential and in vivo vessel-forming ability, showing that functional human blood vessels were maintained in immunodeficient mice for up to 6 months [80]. Similar cytokine cocktails for EC 
differentiation have been reported by other groups [81, 82]. Sriram et al. [81] derived arterial and venous ECs from human embryonic stem cells (hESCs) in serum-free conditions and showed that each of the the derived ECs expresses arterial-specific (NRP1, DLL4, CXCR4) or venous-specific (NRP2, EPHB4) gene expression, respectively. These cells largely maintained their respective phenotypes in vivo, as evidenced by the expression of EFNB2 and EPHB4, though some microvessels formed by arterial ECs acquired expression of venous markers and vice versa over time [81]. Harding et al. [82] also confirmed that the combination of BMP4, VEGF, and bFGF substantially induced proliferative ECs from hiPSCs. They revealed that all three MAPK and the PI3K pathway are responsible for induction of an EC fate and inhibition of the ERK pathway promoted smooth muscle cell differentiation [82]. Ohta et al. [83] utilized coating the tissue culture dishes with short peptide fragments of laminin 411 (LM411-E8), an ECM predominantly expressed in the vascular endothelial basement membrane, for EC differentiation from hiPSCs. They showed higher purity of ECs can be obtained by LM411-E8-coated tissue culture plates than by those coated with matrigel, LM511, type IV collagen or fibronectin [83]. Recently, Paik et al. [84] performed a large-scale single cell RNA-seq for differentiating iPSC-derived ECs at two time-points of differentiation. They revealed that transcriptional heterogeneity with four major subpopulations, 
marked by the enrichment of CLDN5, APLNR, GJA5, and ESM1 genes respectively [84]. Additional single cell RNA-seq profiles in various EC derived by multiple induction methods from hiPSCs would guide us toward a better understanding for inducing proliferative ECs from hiPSCs that are comparable to VESCs identified in primary tissues.

\section{Conclusions}

Identification and understanding of tissue resident and/or circulating VESC is increasingly essential for us to provide those cells for vascular regenerative medicine. In this review, we proposed stem cell criteria for the endothelial lineage that might help to address this issue. Many recent advances, such as, precise cellular fate determination studies in the developing mouse embryo and in vitro differentiating mammalian cells by genome editing, state-of-the-art imaging techniques for those cells, and deep transcriptome analyses by scRNA-seq in vivo and in vitro studies, would help to provide the clues for unveiling VESCs in mammalian systems. Continuous efforts to identify VESCs and define their precise location, origin, surface marker and molecular signatures would lead to the purification of cells with the potential to address increasing clinical demands for tissue regeneration. 


\section{Acknowledgement}

This is a pre-print of an article published in Current Stem Cell Reports. The final authenticated version is available online at: https://doi.org/10.1007/s40778-019-00160-3. 


\section{Fig. 1}

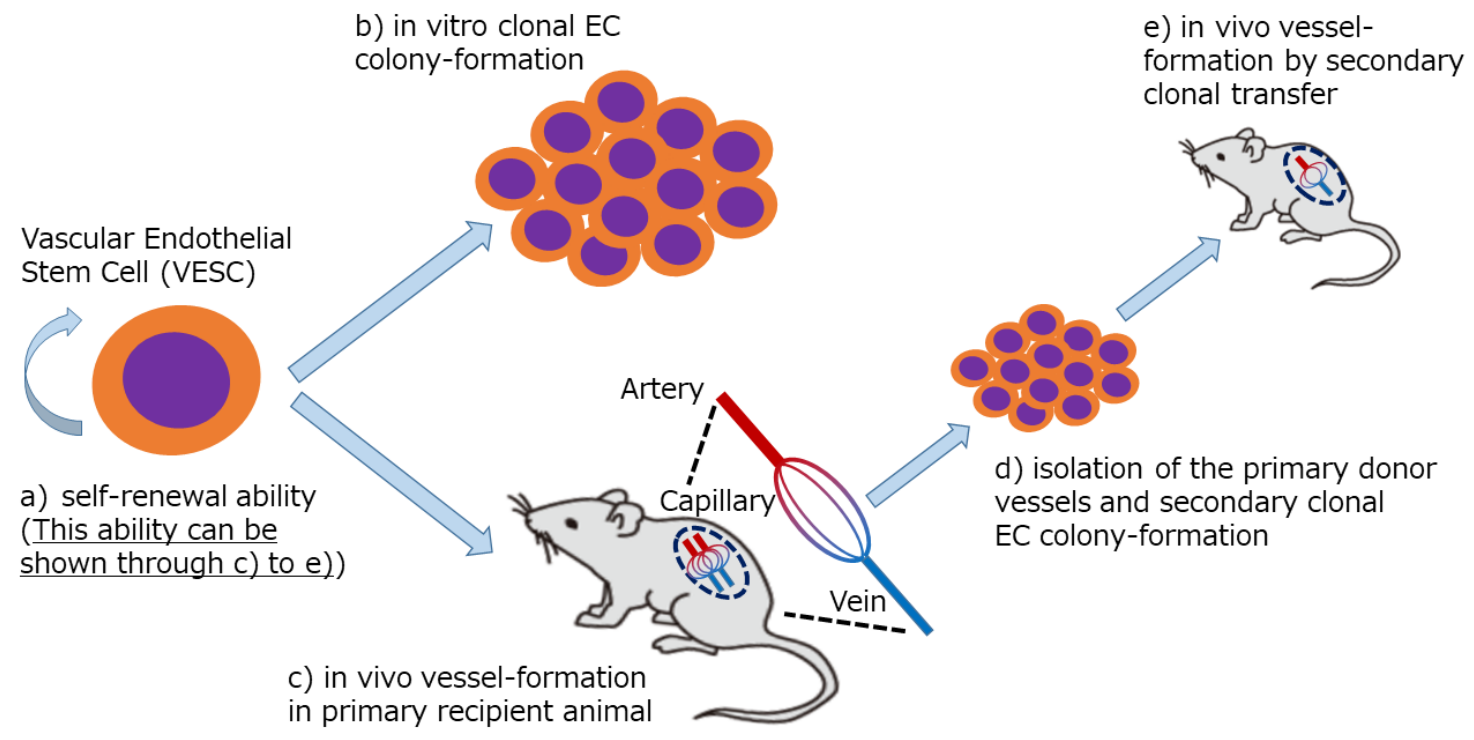

Fig. 1

Criteria for defining vascular endothelial stem cell (VESC) identity.

Endothelial lineage stem cells need to meet the following stem cell criteria: a) selfrenewal ability, b) in vitro clonal proliferation (that can be shown by EC colony-forming potential upon re-plating), and c) in vivo potential of functional vessel-formation (including arterial, venous and capillary ECs) in recipient hosts. Additional data that functionally strengthens the above criteria include; d) isolation of the primary perfused donor-derived vessels and secondary clonal EC colony formation in vitro, and e) secondary in vivo vessel-formation by clonal transfer of the isolated primary donorderived vasculature (confirming self-renewal of VESC within the primary vasculature). 


\section{Reference}

1. Aird WC. Endothelial cell heterogeneity. Cold Spring Harb Perspect Med 2012:2(1):a006429. Doi:10.1101/cshperspect.a006429.

2. Ingram DA, Mead LE, Moore DB, Woodard W, Fenoglio A, Yoder MC. Vessel wall-derived endothelial cells rapidly proliferate because they contain a complete hierarchy of endothelial progenitor cells. Blood 2005:105(7):2783-6. Doi:10.1182/blood-2004-08-3057.

3. Alvarez DF, Huang L, King JA, ElZarrad MK, Yoder MC, Stevens T. Lung microvascular endothelium is enriched with progenitor cells that exhibit vasculogenic capacity. Am $\mathrm{J}$ Physiol Lung Cell Mol Physiol 2008:294(3):L419-30. Doi:10.1152/ajplung.00314.2007.

4. Schniedermann J, Rennecke M, Buttler K, Richter G, Stadtler AM, Norgall S, et al. Mouse lung contains endothelial progenitors with high capacity to form blood and lymphatic vessels. BMC Cell Biol 2010:11:50. Doi:10.1186/1471-2121-11-50.

5. Naito H, Kidoya H, Sakimoto S, Wakabayashi T, Takakura N. Identification and characterization of a resident vascular stem/progenitor cell population in preexisting blood vessels. EMBO J 2012:31(4):842-55. Doi:10.1038/emboj.2011.465.

6. Fang S, Wei J, Pentinmikko N, Leinonen H, Salven P. Generation of functional blood vessels from a single c-kit+ adult vascular endothelial stem cell. PLoS Biol 2012:10(10):e1001407. Doi:10.1371/journal.pbio.1001407.

7. Asahara T, Murohara T, Sullivan A, Silver M, van der Zee R, Li T, et al. Isolation of putative progenitor endothelial cells for angiogenesis. Science 1997:275(5302):964-7.

8. ․ Wakabayashi T, Naito H, Suehiro JI, Lin Y, Kawaji H, Iba T, et al. CD157 Marks Tissue-Resident Endothelial Stem Cells with Homeostatic and Regenerative Properties. Cell Stem Cell 2018:22(3):384-97 e6. Doi:10.1016/j.stem.2018.01.010.

Identifies CD157 as a marker of tissue-resident vascular endothelial stem cells in large arteries and veins of several mouse organs that are capable of clonal expansion and in vivo vessel-formation.

9. - McDonald AI, Shirali AS, Aragon R, Ma F, Hernandez G, Vaughn DA, et al. Endothelial Regeneration of Large Vessels Is a Biphasic Process Driven by Local Cells with Distinct Proliferative Capacities. Cell Stem Cell 2018:23(2):210-25 e6. Doi:10.1016/j.stem.2018.07.011.

Demonstrates that endothelial regeneration of mouse aorta intima is driven by local resident endothelial cells with distinct proliferative capacities and that Atf 3 is required for regeneration of the endothelial lining of large arteries.

10. · Patel J, Seppanen EJ, Rodero MP, Wong HY, Donovan P, Neufeld Z, et al. Functional Definition of Progenitors Versus Mature Endothelial Cells Reveals Key SoxF-Dependent 
Differentiation

Process.

Circulation

2017:135(8):786-805.

Doi:10.1161/CIRCULATIONAHA.116.024754.

Demonstrates an endothelial hierarchy from an endovascular progenitor to a mature differentited endothelial cell and an essential role of the SoxF-dependent transcription factors.

11. Weissman IL. Stem cells: units of development, units of regeneration, and units in evolution. Cell 2000:100(1):157-68.

12. Weissman IL, Anderson DJ, Gage F. Stem and progenitor cells: origins, phenotypes, lineage commitments, and transdifferentiations. Annu Rev Cell Dev Biol 2001:17:387-403. Doi:10.1146/annurev.cellbio.17.1.387.

13. Spradling A, Drummond-Barbosa D, Kai T. Stem cells find their niche. Nature 2001:414(6859):98-104. Doi:10.1038/35102160.

14. Molofsky AV, Pardal R, Iwashita T, Park IK, Clarke MF, Morrison SJ. Bmi-1 dependence distinguishes neural stem cell self-renewal from progenitor proliferation. Nature 2003:425(6961):962-7. Doi:10.1038/nature02060.

15. - Medina RJ, Barber CL, Sabatier F, Dignat-George F, Melero-Martin JM, Khosrotehrani K, et al. Endothelial Progenitors: A Consensus Statement on Nomenclature. Stem Cells Transl Med 2017:6(5):1316-20. Doi:10.1002/sctm.16-0360.

Provides a consensus statement on nomenclature of endothelial progenitor cell and calls for precise terminology based on defining cellular phenotype and function.

16. · Yoder MC. Endothelial stem and progenitor cells (stem cells): (2017 Grover Conference Series). Pulm Circ 2018:8(1):2045893217743950. Doi:10.1177/2045893217743950.

Comprehensive review of the existence of endothelial and progenitor cells in blood vessels.

17. Medina RJ, O'Neill CL, O'Doherty TM, Wilson SE, Stitt AW. Endothelial progenitors as tools to study vascular disease. Stem Cells Int 2012:2012:346735. Doi:10.1155/2012/346735. 18. Case J, Mead LE, Bessler WK, Prater D, White HA, Saadatzadeh MR, et al. Human CD34+AC133+VEGFR-2+ cells are not endothelial progenitor cells but distinct, primitive hematopoietic progenitors. Exp Hematol 2007:35(7):1109-18. Doi:10.1016/j.exphem.2007.04.002.

19. Wu X, Lensch MW, Wylie-Sears J, Daley GQ, Bischoff J. Hemogenic endothelial progenitor cells isolated from human umbilical cord blood. Stem Cells 2007:25(11):2770-6. Doi:10.1634/stemcells.2006-0783.

20. Yoder MC. Is endothelium the origin of endothelial progenitor cells? Arterioscler Thromb Vasc Biol 2010:30(6):1094-103. Doi:10.1161/ATVBAHA.109.191635.

21. Mund JA, Estes ML, Yoder MC, Ingram DA, Jr., Case J. Flow cytometric identification and functional characterization of immature and mature circulating endothelial cells. 
Arterioscler Thromb Vasc Biol 2012:32(4):1045-53. Doi:10.1161/ATVBAHA.111.244210.

22. Basile DP, Yoder MC. Circulating and tissue resident endothelial progenitor cells. J Cell Physiol 2014:229(1):10-6. Doi:10.1002/jcp.24423.

23. Medina RJ, O'Neill CL, Humphreys MW, Gardiner TA, Stitt AW. Outgrowth endothelial cells: characterization and their potential for reversing ischemic retinopathy. Invest Ophthalmol Vis Sci 2010:51(11):5906-13. Doi:10.1167/iovs.09-4951.

24. Yoon CH, Hur J, Park KW, Kim JH, Lee CS, Oh IY, et al. Synergistic neovascularization by mixed transplantation of early endothelial progenitor cells and late outgrowth endothelial cells: the role of angiogenic cytokines and matrix metalloproteinases. Circulation 2005:112(11):1618-27. Doi:10.1161/CIRCULATIONAHA.104.503433.

25. Medina RJ, O'Neill CL, Sweeney M, Guduric-Fuchs J, Gardiner TA, Simpson DA, et al. Molecular analysis of endothelial progenitor cell (EPC) subtypes reveals two distinct cell populations with different identities. BMC Med Genomics 2010:3:18. Doi:10.1186/1755-8794$3-18$.

26. Asahara T, Kawamoto A, Masuda H. Concise review: Circulating endothelial progenitor cells for vascular medicine. Stem Cells 2011:29(11):1650-5. Doi:10.1002/stem.745.

27. Mukai N, Akahori T, Komaki M, Li Q, Kanayasu-Toyoda T, Ishii-Watabe A, et al. A comparison of the tube forming potentials of early and late endothelial progenitor cells. Exp Cell Res 2008:314(3):430-40. Doi:10.1016/j.yexcr.2007.11.016.

28. Medina RJ, O'Neill CL, O'Doherty TM, Knott H, Guduric-Fuchs J, Gardiner TA, et al. Myeloid angiogenic cells act as alternative M2 macrophages and modulate angiogenesis through interleukin-8. Mol Med 2011:17(9-10):1045-55. Doi:10.2119/molmed.2011.00129.

29. Cheng CC, Chang SJ, Chueh YN, Huang TS, Huang PH, Cheng SM, et al. Distinct angiogenesis roles and surface markers of early and late endothelial progenitor cells revealed by functional group analyses. BMC Genomics 2013:14:182. Doi:10.1186/1471-2164-14-182.

30. Lin Y, Weisdorf DJ, Solovey A, Hebbel RP. Origins of circulating endothelial cells and endothelial outgrowth from blood. J Clin Invest 2000:105(1):71-7. Doi:10.1172/JCI8071.

31. Ingram DA, Mead LE, Tanaka H, Meade V, Fenoglio A, Mortell K, et al. Identification of a novel hierarchy of endothelial progenitor cells using human peripheral and umbilical cord blood. Blood 2004:104(9):2752-60. Doi:10.1182/blood-2004-04-1396.

32. Yoder MC, Mead LE, Prater D, Krier TR, Mroueh KN, Li F, et al. Redefining endothelial progenitor cells via clonal analysis and hematopoietic stem/progenitor cell principals. Blood 2007:109(5):1801-9. Doi:10.1182/blood-2006-08-043471.

33. Hirschi KK, Ingram DA, Yoder MC. Assessing identity, phenotype, and fate of endothelial progenitor cells. Arterioscler Thromb Vasc Biol 2008:28(9):1584-95. Doi:10.1161/ATVBAHA.107.155960. 
34. - Tasev D, Koolwijk P, van Hinsbergh VW. Therapeutic Potential of HumanDerived Endothelial Colony-Forming Cells in Animal Models. Tissue Eng Part B Rev 2016:22(5):371-82. Doi:10.1089/ten.TEB.2016.0050.

Comprehensive review of in vivo studies indicating the potential use of human-derived ECFCs to induce neovascularization for tissue regeneration.

35. Critser PJ, Yoder MC. Endothelial colony-forming cell role in neoangiogenesis and tissue repair. Curr Opin Organ Transplant 2010:15(1):68-72. Doi:10.1097/MOT.0b013e32833454b5. 36. Tura O, Skinner EM, Barclay GR, Samuel K, Gallagher RC, Brittan M, et al. Late outgrowth endothelial cells resemble mature endothelial cells and are not derived from bone marrow. Stem Cells 2013:31(2):338-48. Doi:10.1002/stem.1280.

37. ' Paschalaki KE, Randi AM. Recent Advances in Endothelial Colony Forming Cells Toward Their Use in Clinical Translation. Front Med (Lausanne) 2018:5:295. Doi:10.3389/fmed.2018.00295.

Recent review of the translational applications of ECFC under investigation of preclinical models for autologous cell therapy, gene therapy and tissue bioengineering.

38. Banno K, Yoder MC. Tissue regeneration using endothelial colony-forming cells: promising cells for vascular repair. Pediatr Res 2018:83(1-2):283-90. Doi:10.1038/pr.2017.231. 39. - Keighron C, Lyons CJ, Creane M, O'Brien T, Liew A. Recent Advances in Endothelial Progenitor Cells Toward Their Use in Clinical Translation. Front Med (Lausanne) 2018:5:354. Doi:10.3389/fmed.2018.00354.

Comprehensive review of clinical and preclinical studies using the term "EPC", calling for prudent use of "EPC" by researchers.

40. Jimenez-Quevedo P, Gonzalez-Ferrer JJ, Sabate M, Garcia-Moll X, Delgado-Bolton R, Llorente L, et al. Selected CD133(+) progenitor cells to promote angiogenesis in patients with refractory angina: final results of the PROGENITOR randomized trial. Circ Res 2014:115(11):950-60. Doi:10.1161/CIRCRESAHA.115.303463.

41. Arici V, Perotti C, Fabrizio C, Del Fante C, Ragni F, Alessandrino F, et al. Autologous immuno magnetically selected CD133+ stem cells in the treatment of no-option critical limb ischemia: clinical and contrast enhanced ultrasound assessed results in eight patients. $J$ Transl Med 2015:13:342. Doi:10.1186/s12967-015-0697-4.

42. Mutirangura P, Ruangsetakit C, Wongwanit C, Chinsakchai K, Porat Y, Belleli A, et al. Enhancing limb salvage by non-mobilized peripheral blood angiogenic cell precursors therapy in patients with critical limb ischemia. J Med Assoc Thai 2009:92(3):320-7.

43. Kawamoto A, Katayama M, Handa N, Kinoshita M, Takano H, Horii M, et al. Intramuscular transplantation of G-CSF-mobilized CD34(+) cells in patients with critical limb ischemia: a phase I/IIa, multicenter, single-blinded, dose-escalation clinical trial. Stem 
Cells 2009:27(11):2857-64. Doi:10.1002/stem.207.

44. Kinoshita M, Fujita Y, Katayama M, Baba R, Shibakawa M, Yoshikawa K, et al. Longterm clinical outcome after intramuscular transplantation of granulocyte colony stimulating factor-mobilized CD34 positive cells in patients with critical limb ischemia. Atherosclerosis 2012:224(2):440-5. Doi:10.1016/j.atherosclerosis.2012.07.031.

45. Wang XX, Zhang FR, Shang YP, Zhu JH, Xie XD, Tao QM, et al. Transplantation of autologous endothelial progenitor cells may be beneficial in patients with idiopathic pulmonary arterial hypertension: a pilot randomized controlled trial. J Am Coll Cardiol 2007:49(14):1566-71. Doi:10.1016/j.jacc.2006.12.037.

46. Granton J, Langleben D, Kutryk MB, Camack N, Galipeau J, Courtman DW, et al. Endothelial NO-Synthase Gene-Enhanced Progenitor Cell Therapy for Pulmonary Arterial Hypertension: The PHACeT Trial. Circ Res 2015:117(7):645-54. Doi:10.1161/CIRCRESAHA.114.305951.

47. D'Avola D, Fernandez-Ruiz V, Carmona-Torre F, Mendez M, Perez-Calvo J, Prosper F, et al. Phase 1-2 pilot clinical trial in patients with decompensated liver cirrhosis treated with bone marrow-derived endothelial progenitor cells. Transl Res 2017:188:80-91 e2. Doi:10.1016/j.trsl.2016.02.009.

48. Maldonado GE, Perez CA, Covarrubias EE, Cabriales SA, Leyva LA, Perez JC, et al. Autologous stem cells for the treatment of post-mastectomy lymphedema: a pilot study. Cytotherapy 2011:13(10):1249-55. Doi:10.3109/14653249.2011.594791.

49. Lara-Hernandez R, Lozano-Vilardell P, Blanes P, Torreguitart-Mirada N, Galmes A, Besalduch J. Safety and efficacy of therapeutic angiogenesis as a novel treatment in patients with critical limb ischemia. Ann Vasc Surg 2010:24(2):287-94. Doi:10.1016/j.avsg.2009.10.012. 50. Tanaka R, Masuda H, Kato S, Imagawa K, Kanabuchi K, Nakashioya C, et al. Autologous G-CSF-mobilized peripheral blood CD34+ cell therapy for diabetic patients with chronic nonhealing ulcer. Cell Transplant 2014:23(2):167-79. Doi:10.3727/096368912X658007.

51. Zhu J, Song J, Yu L, Zheng H, Zhou B, Weng S, et al. Safety and efficacy of autologous thymosin beta 4 pre-treated endothelial progenitor cell transplantation in patients with acute ST segment elevation myocardial infarction: A pilot study. Cytotherapy 2016:18(8):1037-42. Doi:10.1016/j.jcyt.2016.05.006.

52. Zhu JH, Wang XX, Zhang FR, Shang YP, Tao QM, Zhu JH, et al. Safety and efficacy of autologous endothelial progenitor cells transplantation in children with idiopathic pulmonary arterial hypertension: open-label pilot study. Pediatr Transplant 2008:12(6):6505. Doi:10.1111/j.1399-3046.2007.00863.x.

53. Sato T, van Es JH, Snippert HJ, Stange DE, Vries RG, van den Born M, et al. Paneth cells constitute the niche for Lgr5 stem cells in intestinal crypts. Nature 2011:469(7330):415-8. 
Doi:10.1038/nature09637.

54. Beumer J, Clevers H. Regulation and plasticity of intestinal stem cells during homeostasis and regeneration. Development 2016:143(20):3639-49. Doi:10.1242/dev.133132. 55. Sawai CM, Babovic S, Upadhaya S, Knapp D, Lavin Y, Lau CM, et al. Hematopoietic Stem Cells Are the Major Source of Multilineage Hematopoiesis in Adult Animals. Immunity 2016:45(3):597-609. Doi:10.1016/j.immuni.2016.08.007.

56. Gonzales KAU, Fuchs E. Skin and Its Regenerative Powers: An Alliance between Stem Cells and Their Niche. Dev Cell 2017:43(4):387-401. Doi:10.1016/j.devcel.2017.10.001.

57. Cheung TH, Rando TA. Molecular regulation of stem cell quiescence. Nat Rev Mol Cell Biol 2013:14(6):329-40. Doi:10.1038/nrm3591.

58. Schwartz SM, Benditt EP. Clustering of replicating cells in aortic endothelium. Proc Natl Acad Sci U S A 1976:73(2):651-3.

59. Kunz J, Schreiter B, Schubert B, Voss K, Krieg K. [Experimental investigations on the regeneration of aortic endothelial cells. Automatic and visual evaluation of autoradiograms (author's transl)]. Acta Histochem 1978:61(1):53-63.

60. Prescott MF, Muller KR. Endothelial regeneration in hypertensive and genetically hypercholesterolemic rats. Arteriosclerosis 1983:3(3):206-14.

61. Manderson JA, Campbell GR. Venous response to endothelial denudation. Pathology 1986:18(1):77-87.

62. Goodell MA, Brose K, Paradis G, Conner AS, Mulligan RC. Isolation and functional properties of murine hematopoietic stem cells that are replicating in vivo. J Exp Med 1996:183(4):1797-806.

63. · Yu QC, Song W, Wang D, Zeng YA. Identification of blood vascular endothelial stem cells by the expression of protein C receptor. Cell Res 2016:26(10):1079-98. Doi:10.1038/cr.2016.85.

Identifies Procr expressing endothelial cells as VESCs in the adult mammary, skin and retina and provides evidence that Procr+ VESCs are bipotent cells of endothelial cells and pericytes.

64. · He L, Vanlandewijck M, Mae MA, Andrae J, Ando K, Del Gaudio F, et al. Single-cell RNA sequencing of mouse brain and lung vascular and vessel-associated cell types. Sci Data 2018:5:180160. Doi:10.1038/sdata.2018.160.

Provides the database constituting a comprehensive molecular atlas of vascular and vesselassociated cell types in the mouse brain and lung.

65. - Sabbagh MF, Heng JS, Luo C, Castanon RG, Nery JR, Rattner A, et al. Transcriptional and epigenomic landscapes of CNS and non-CNS vascular endothelial cells. Elife 2018:7. Doi:10.7554/eLife.36187. 
Demonstrates the comparison of the transcriptome, accessible chromatin, and DNA methylome landscapes from mouse brain, liver, lung, and kidney ECs and provides the evidence of inter-tissue and intra-tissue EC heterogeneity.

66. Critser PJ, Voytik-Harbin SL, Yoder MC. Isolating and defining cells to engineer human blood vessels. Cell Prolif 2011:44 Suppl 1:15-21. Doi:10.1111/j.1365-2184.2010.00719.x.

67. Melero-Martin JM, Khan ZA, Picard A, Wu X, Paruchuri S, Bischoff J. In vivo vasculogenic potential of human blood-derived endothelial progenitor cells. Blood 2007:109(11):4761-8. Doi:10.1182/blood-2006-12-062471.

68. Hirschi KK, Dejana E. Resident Endothelial Progenitors Make Themselves at Home. Cell Stem Cell 2018:23(2):153-5. Doi:10.1016/j.stem.2018.07.014.

69. - Campanelli R, Codazzi AC, Poletto V, Abba C, Catarsi P, Fois G, et al. Kinetic and Angiogenic Activity of Circulating Endothelial Colony Forming Cells in Patients with Infantile Haemangioma Receiving Propranolol. Thromb Haemost 2019. Doi:10.1055/s-00381676855 .

Provides the evaluation of the frequency of circulating ECFCs in patients with IH before and after receiving propranolol and implicates their role in IH pathogenesis.

70. Baker CD, Balasubramaniam V, Mourani PM, Sontag MK, Black CP, Ryan SL, et al. Cord blood angiogenic progenitor cells are decreased in bronchopulmonary dysplasia. Eur Respir J 2012:40(6):1516-22. Doi:10.1183/09031936.00017312.

71. Borghesi A, Massa M, Campanelli R, Bollani L, Tzialla C, Figar TA, et al. Circulating endothelial progenitor cells in preterm infants with bronchopulmonary dysplasia. Am J Respir Crit Care Med 2009:180(6):540-6. Doi:10.1164/rccm.200812-1949OC.

72. Alphonse RS, Vadivel A, Fung M, Shelley WC, Critser PJ, Ionescu L, et al. Existence, functional impairment, and lung repair potential of endothelial colony-forming cells in oxygen-induced arrested alveolar growth. Circulation 2014:129(21):2144-57. Doi:10.1161/CIRCULATIONAHA.114.009124.

73. Margariti A, Winkler B, Karamariti E, Zampetaki A, Tsai TN, Baban D, et al. Direct reprogramming of fibroblasts into endothelial cells capable of angiogenesis and reendothelialization in tissue-engineered vessels. Proc Natl Acad Sci U S A 2012:109(34):13793-8. Doi:10.1073/pnas.1205526109.

74. Ginsberg M, James D, Ding BS, Nolan D, Geng F, Butler JM, et al. Efficient direct reprogramming of mature amniotic cells into endothelial cells by ETS factors and TGFbeta suppression. Cell 2012:151(3):559-75. Doi:10.1016/j.cell.2012.09.032.

75. Morita R, Suzuki M, Kasahara H, Shimizu N, Shichita T, Sekiya T, et al. ETS transcription factor ETV2 directly converts human fibroblasts into functional endothelial cells. Proc Natl Acad Sci U S A 2015:112(1):160-5. Doi:10.1073/pnas.1413234112. 
76. - Lee S, Park C, Han JW, Kim JY, Cho K, Kim EJ, et al. Direct Reprogramming of Human Dermal Fibroblasts Into Endothelial Cells Using ER71/ETV2. Circ Res 2017:120(5):848-61. Doi:10.1161/CIRCRESAHA.116.309833.

Utilizes various combination of $7 \mathrm{EC}$ transcriptional factors and demonstrates ETV2 alone can directly reprogram human postnatal cells to functional, mature ECs.

77. Wareing S, Mazan A, Pearson S, Gottgens B, Lacaud G, Kouskoff V. The Flk1-Cremediated deletion of ETV2 defines its narrow temporal requirement during embryonic hematopoietic development. Stem Cells 2012:30(7):1521-31. Doi:10.1002/stem.1115.

78. Moore JC, Sheppard-Tindell S, Shestopalov IA, Yamazoe S, Chen JK, Lawson ND. Posttranscriptional mechanisms contribute to Etv2 repression during vascular development. Dev Biol 2013:384(1):128-40. Doi:10.1016/j.ydbio.2013.08.028.

79. '- Gallego-Perez D, Pal D, Ghatak S, Malkoc V, Higuita-Castro N, Gnyawali S, et al. Topical tissue nano-transfection mediates non-viral stroma reprogramming and rescue. Nat Nanotechnol 2017:12(10):974-9. Doi:10.1038/nnano.2017.134.

Demonstrates a novel non-viral approach to topically reprogram tissue through a nanochannelled device to reprogram keratinocytes into neurons or ECs.

80. Prasain N, Lee MR, Vemula S, Meador JL, Yoshimoto M, Ferkowicz MJ, et al. Differentiation of human pluripotent stem cells to cells similar to cord-blood endothelial colony-forming cells. Nat Biotechnol 2014:32(11):1151-7. Doi:10.1038/nbt.3048.

81. Sriram G, Tan JY, Islam I, Rufaihah AJ, Cao T. Efficient differentiation of human embryonic stem cells to arterial and venous endothelial cells under feeder- and serum-free conditions. Stem Cell Res Ther 2015:6:261. Doi:10.1186/s13287-015-0260-5.

82. · Harding A, Cortez-Toledo E, Magner NL, Beegle JR, Coleal-Bergum DP, Hao D, et al. Highly Efficient Differentiation of Endothelial Cells from Pluripotent Stem Cells Requires the MAPK and the PI3K Pathways. Stem Cells 2017:35(4):909-19. Doi:10.1002/stem.2577.

Demonstrates the efficient EC differentiation from PSCs and investigates molecular pathways responsible for induction of an EC fate

83. · Ohta R, Niwa A, Taniguchi Y, Suzuki NM, Toga J, Yagi E, et al. Laminin-guided highly efficient endothelial commitment from human pluripotent stem cells. Sci Rep 2016:6:35680. Doi:10.1038/srep35680.

Provides the important role and contribution of the extracellular matrix during differentiation from PSCs and demonstrated that a short fragment of laminin 411 yields highly-purified ECs without cell sorting.

84. ' - Paik DT, Tian L, Lee J, Sayed N, Chen IY, Rhee S, et al. Large-Scale Single-Cell RNASeq Reveals Molecular Signatures of Heterogeneous Populations of Human Induced Pluripotent Stem Cell-Derived Endothelial Cells. Circ Res 2018:123(4):443-50. 
Doi:10.1161/CIRCRESAHA.118.312913.

Provides single-cell transcriptome of differenting PSCs toward the EC lineage and identifies four subpopulation based on molecular signatures. 